\title{
Early agricultural development and environmental effects in the Neolithic Longdong basin (eastern Gansu)
}

\author{
ZHOU Xin Ying $^{1}$, LI XiaoQiang ${ }^{1,2^{*}}$, ZHAO KeLiang $^{1,3}$, DODSON John ${ }^{4}$, SUN Nan $^{1,3}$ \& \\ YANG Qing ${ }^{1,3}$ \\ ${ }^{1}$ State Key Laboratory of Loess and Quaternary Geology, Institute of Earth Environment, Chinese Academy of Sciences, Xi'an 710075, China; \\ ${ }^{2}$ Laboratory of Human Evolution and Archeological Science, Institute of Vertebrate Paleontology and Paleoanthropology, Chinese Academy of \\ Sciences, Beijing 100044, China; \\ ${ }^{3}$ Graduate University of Chinese Academy of Sciences, Beijing 100049, China; \\ ${ }^{4}$ Institute for Environmental Research, the Australian Nuclear Science and Technology Organization, Sydney, NSW 1001, Australia
}

Received August 6, 2010; accepted November 16, 2010

\begin{abstract}
Neolithic agricultural development and environmental effects in the Longdong area were reconstructed using a synthetic approach, investigating pollen, charcoal, and seed remains for two cultural layer sections and five flotation sites. Results show that Neolithic agriculture in the Longdong area had a simple organization and was dominated by the production of common millet, especially in the early and middle Yangshao age. After the late Yangshao age, Neolithic agriculture developed into a more complex structure, dominated by both common and foxtail millet and the cultivation of rice and soybeans. The production of foxtail millet gradually increased through the Neolithic period, reaching its highest point during the Qijia culture. Soybeans were first cultivated during the late Yangshao culture, approximately $5000 \mathrm{cal}$ a BP. Rice production began no later than $4800 \mathrm{cal}$ a BP, and continued to exist in the Qijia culture, approximately $4000 \mathrm{cal}$ a BP. Agricultural production in Neolithic Longdong, specifically in the "Yuan" area of the loess plateau, developed as a shrub and grass dominated landscape. Vegetation in the river valleys was partly covered with Picea, Tusga, and Quercus coniferous and broadleaf mixed forests. Agricultural activity during the Neolithic period caused an increase in farmland on the loess tableland and a decrease in the abundance of shrub and grassland in the Longdong area. When farmlands were abandoned, vegetation recovered with Hippophae-, Rosaceae-, Ephedra-, and Leguminosae-dominated shrublands and Artemisia-dominated grasslands.
\end{abstract}

eastern Gansu, Neolithic, early agriculture, environmental effect, pollen, seed

Citation: Zhou X Y, Li X Q, Zhao K L, et al. Early agricultural development and environmental effects in the Neolithic Longdong basin (eastern Gansu). Chinese Sci Bull, 2011, 56: 762-771, doi: 10.1007/s11434-010-4286-X

In recent decades, synthetic studies of ancient human activities and paleo-environmental change, including archeological, geological, and botanical methodologies have increased nationally and internationally. Biological records, such as pollen, phytoliths, charcoal, and seeds, have been the main focus of investigations of early agricultural activities and their environmental impacts [1-4]. Charred seed and fruit remains from a given culture can offer direct evidence for the types of plants cultivated during the early stages of agri-

*Corresponding author (email: lixiaoqiang@ivpp.ac.cn) cultural development. Pollen and charcoal analysis can provide evidence of vegetation history for a given area, as they point to human intervention (e.g. slash and burn) in the landscape $[3,4]$.

Dry farming agricultural activities originated in the Yellow River basin in northern China, an area recognized as the heart of ancient Chinese civilization. Today, systematic research of the early agricultural evolutionary process and the environmental effects of human intervention in northern China has become an important field [2,5]. It is well established that common millet and foxtail millet were the 
dominant species among agricultural assemblages of various Neolithic societies of northern China [6,7]. In addition, the occurrence of crops, such as rice, soybeans, buckwheat, and wheat since at least $4000 \mathrm{cal}$ a BP in Neolithic northern China seems to have promoted the development of early diverse agriculture and provided the physical and cultural foundations for the origin of Chinese civilization [6,8-10]. However, the origins and expansion of early Chinese agriculture still requires further study. In addition, more archaeological evidence is needed to generate a biological index of early agriculture characteristics in various geological units. Such studies will facilitate further investigations on environmental changes in different historical phases in Neolithic northern China.

The Longdong basin is located west of the Loess Plateau, and it is a relatively isolated geological unit. Vegetation of the Longdong basin was dominated by shrub-grassland during the Holocene optimum period [11]. Under these conditions, the Neolithic farmer exploited the Longdong area through the entire Neolithic age. Studies have shown that Neolithic cultural sequences in the Longdong area included the Yangshao culture, the lower-layer Changshan culture, the Majiayao culture, and the Qijia culture [12,13]. A large amount of cultural remains from the Neolithic period have survived in the Longdong area, providing an integrated sequence of Neolithic cultures and abundant research materials for the study of bio-archeological and paleo-global changes. However, development of agriculture in the Longdong area during the Neolithic period is still poorly understood. Published studies are lacking across this field of research, except for the discovery of cultivated rice at
Houguanzhai dating to the late Yangshao period (identified as a type between Japonica and Indica varieties) [14]. To further understand the character of early agriculture in this region, and bio-environmental changes resulting from human intervention, this paper presents updated evidence of pollen and charred seeds, along with high resolution $\mathrm{AMS}^{14} \mathrm{C}$ data. This information can be used to better examine agricultural development and changes in vegetation in the Longdong basin area during different phases of the Neolithic period.

\section{Study area and background}

The Longdong basin $\left(106^{\circ} 20^{\prime}-108^{\circ} 45^{\prime} \mathrm{E} ; 35^{\circ} 15^{\prime}-37^{\circ} 10^{\prime} \mathrm{N}\right)$ is located in eastern Gansu, between the Ziwuling and Liupan mountains (Figure 1). The basin has a warm, semihumid climate. Annual precipitation in the Longdong area is $350-650 \mathrm{~mm}$, usually ranging from $500-550 \mathrm{~mm}$ during the summer monsoon season [15]. The altitude of Longdong is 885-2089 $\mathrm{m}$ a.s.l. Most of the Longdong area, including Dongzhi Yuan (largest loess tableland in China) is covered by loesses, which are $200 \mathrm{~m}$ thick on average. The main rivers of the Longdong area are the Jing, Malian, $\mathrm{Pu}, \mathrm{He}$, Malan, and Gan. Artemisia grasslands, dominated by $\mathrm{Ar}$ temisia sacrorum and Artemisia giraldii, and old world bluestem grasslands, dominated by Bothriochloa ischcemum and Leymus sp., are common in southern and central Longdong. Drought tolerant grasslands dominated by Stipa bungeana are common in the northern parts of the region $[13,14]$. Warm, temperate, deciduous, secondary forests,

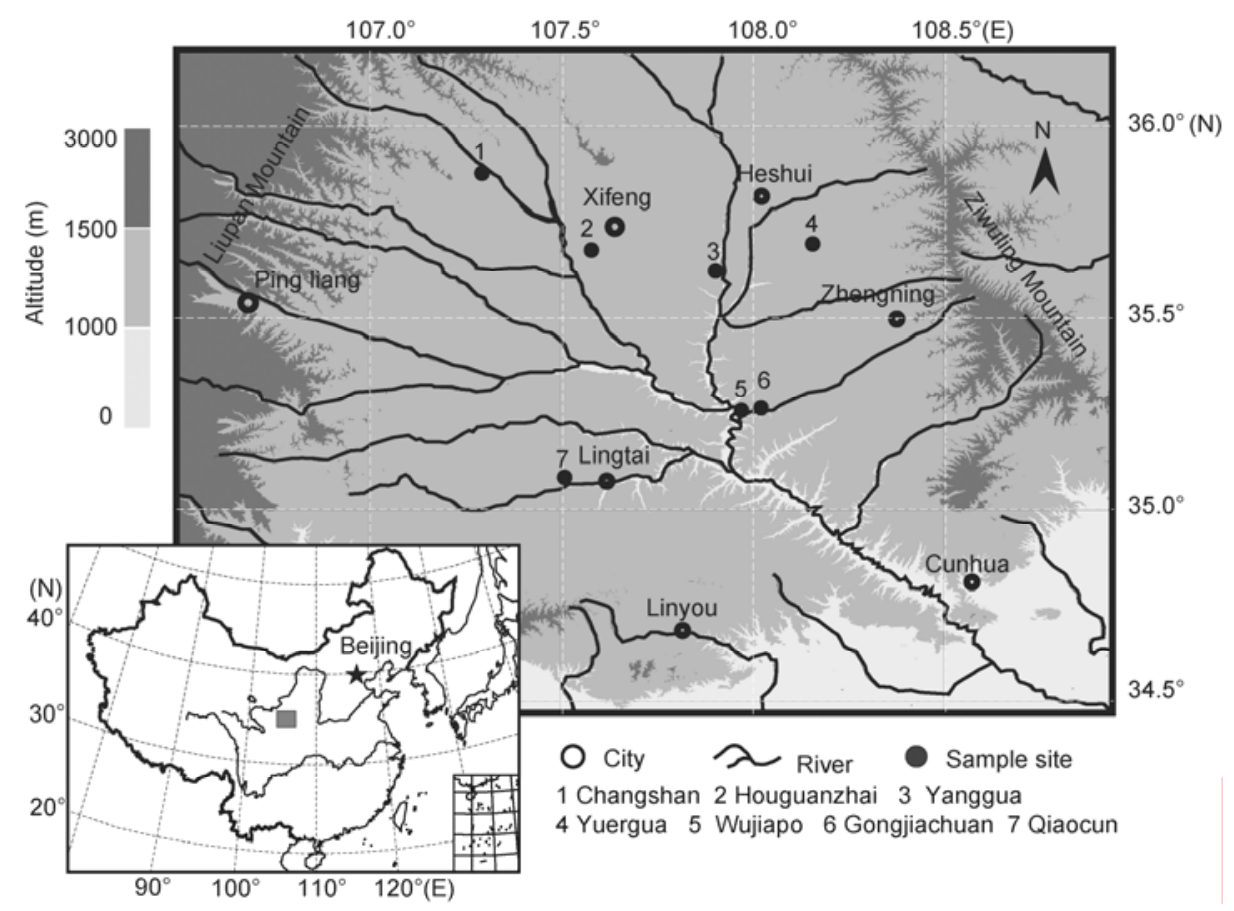

Figure 1 Study area and sample sites. 
dominated by Quercus acutissima, Pinus tabulaeformis, Platycladus orientalis, and Ulmus sp., are distributed in the gravel- and sand-based areas of the upper and middle reaches of the Jing River. The typical shrubs, including Hippophae sp., Rosa primula, Ostryopsis davidiana, Lespedeza bicolor, and Zizyphus jujube, are widely distributed across the Longdong area. Because of reclamation of farmland in the past one hundred years, the natural vegetation was nearly destroyed and has been replaced by artificial or secondary vegetation. The main crops of the Longdong basin currently include wheat (Triticum aestivum), corn (Zea mays), sorghum (Sorghum bicdor), foxtail millet (Setaria italica), common millet (Panicum miliaceum), soybean (Glycine max), and potato (Solanum tuberosum) [16,17].

A pre-Yangshao culture has not yet been discovered in the Longdong basin. The earliest Neolithic culture is early Yangshao. Settlements have been discovered at Dongzhuang, Mengqiao, and Gongjiachuan, which are generally dated to 7000-6000 cal a BP [12]. The remains of the middle Yangshao culture (6000-5000 cal a BP) are abundant in Longdong. Middle Yanshao sites are much more abundant than early Yangshao sites, which indicates the relative prosperity of this agricultural culture [12,18,19]. The Changshan Lower Layer culture, which is considered to be the transition between middle Yangshao culture and subsequent cultures, follows with fewer sites and smaller settlements. ${ }^{14} \mathrm{C}$ data from sites at Changshan and Dadiwan show that the age of this culture is approximately $4900 \mathrm{cal}$ a BP [20,21]. One important culture type, the Houguanzhai type, is considered to be synchronous with or a little later than late Yangshao culture [22]. The Qijia culture was the last prosperous group in the Neolithic period in the Longdong basin. The Qijia were widely distributed across the basin, and left evidence of many large sites, such as Qiaocun and Yuergua $[18,23]$. Previous studies have shown that the Qijia culture developed out of either the Majiayao culture, a group that originated in the mountainous areas of southern Ningxia, or the native Changshan Lower Layer culture. The Qijia culture is commonly dated to $4300-3900 \mathrm{cal}$ a BP $[12,24]$.

\section{Methods and materials}

During the 1970s, archaeologist invented the water flotation method for studying paleobotanical material. This method has become popular for archeological investigations in China in recent years. The method is used as a means to collect animal and plant remains from the layers and ash pits of archeological sites [25-27]. The Neolithic remains obtained by flotation usually contain large amounts of charred crop seeds. Compared to other types of crop remains, such as straw, impressions, and leaves, charred seeds occur in large quantities, and are easy to identify for quantitative analyses. Statistical analyses of absolute quantity and present probability of different seeds at a given site are now accepted as the most important values to evaluate to study agricultural structures of ancient societies [6].

The materials for this study were gathered from seven Neolithic sites in the Longdong basin: Gongjiachuan, Wujiapo, Changshan, Yanggua, Houguanzhai, Qiaocun and Yuergua (Figure 1). Seed samples were collected from these sites using the flotation method. The samples were collected at intervals of $20 \mathrm{~cm}$ in sections containing cultural layers that were deposited as horizons extending in stratigraphic layers without any disruptions (e.g. ash pits or burials). The volume of each sample was generally 40 liters as the cultural layers contained fewer seeds. Large amounts of soil were needed to collect a statistically significant sample. In some isolated cultural deposits, two samples were collected, and the volume of each sample was 20 liters. The cell number per square inch of flotation sieve was $50(0.3 \mathrm{~mm}$ mesh). The floated samples were air-dried and collected in sample bags and separated at the laboratory. Selected seed samples were identified using a stereomicroscope.

As is common for most archaeological sites, modern seeds can be transported into archaeological layers by rodents or recent cultivation activities. Most modern or neoteric seeds found in the flotation samples were not charred and were easy to distinguish. However, some seeds were charred and thus were difficult to visually distinguish, potentially causing errors in the data set. In this study, alkali tests were performed on suspicious samples to reduce the risk of errors. First, these seed samples were put into a $1 \%$ $\mathrm{NaOH}$ solution in a test tube, and then put into a water bath in a constant-temperature oscillator set to $60^{\circ} \mathrm{C}$ for $2 \mathrm{~h}$. This procedure was done repeatedly until the liquid was completely reactionless and clean. At this point, modern or neoteric seeds would have dissolved (in full or in part) because they are often only charred on their surfaces. Thus, the interior of the seeds, composed of primarily starch, fiber, protein, and oil, dissolves slowly during the alkali procedure. In contrast, charred ancient seeds, which have hardened over thousands of years, remain intact, except for the absorption of some humic acid [28].

There were large amounts of cultural remains deposited in the Longdong area. Two sections with cultural layers were chosen for this study. The Houguangzhai section contained a Yangshao cultural layer located on the edge of a loess tableland, $6 \mathrm{~km}$ southwest of Xifeng in Gansu. The Houguangzhai section was $5.4 \mathrm{~m}$ thick and, according to its color and structure, could be subdivided into four layers: (1) $0-40 \mathrm{~cm}$, the modern cultivated layer; (2) 30-270 cm, a fine sandy aqueous loess layer, containing little charcoal, with a sandy layer deposited horizontally at its base; (3) $270-500 \mathrm{~cm}$, a cultural layer, containing large pieces of charcoal and red mud formed pottery; and (4) 500-540 cm, a fine sandy aeolian loess layer. The second section, the Qiaocun section, is located $20 \mathrm{~km}$ northwest of Lingtai. This section was $5.4 \mathrm{~m}$ thick and could be subdivided into 4 layers: (1) $0-40 \mathrm{~cm}$, a brownish modern cultivated layer; (2) 40-80 cm, a yellow fine sandy loess 
layer with $\mathrm{CaCO}_{2}$ grains; (3) $80-320 \mathrm{~cm}$, a cultural layer, containing much charcoal and red and brown pottery; and (4) $320-400 \mathrm{~cm}$, a fine sandy aeolian loess layer.

Because of the low pollen concentration of this loess sediment, an integrative method of sieving and heavy liquid was used for pollen analyses [29]. Sixteen pollen and charcoal samples were analyzed in each section, and the absolute pollen count of most samples was over 250 . The concentration of charcoal in these sections was quantified using the point count method [30,31].

\section{Results}

\subsection{Chronological structure and culture period}

Six charcoal samples from the Houguanzhai section and one seed and three charcoal samples from the Qiaocun section were chosen for $\mathrm{AMS}^{14} \mathrm{C}$ dating. AMS data collection was performed in an accelerator mass spectrometry lab at the Australian Nuclear Science and Technology Organisation (ANSTO), and ages were calculated from uncalibrated dates using the Calib 5.1 program [32]. These data show that the age of the cultural layer discovered in the Houguanzhai section is $4500-4850 \mathrm{cal}$ a BP (Table 1), putting it a little later than the original estimation based on archaeological field investigation [22]. This date also makes it contemporary with the Banshan type of Majiayao culture. The age of the cultural layer in the Qiaocun section is 3900-4150 cal a BP (Table 1), associating it with the Qijia culture, and affirming the date of the other remains discovered around Qiaocun. Besides these two sites, the culture type assessments of other investigated sites in the region have been primarily based on archaeological investigations and excavation reports [18,20,23,33-35]. The age of the samples (Table 2) from the archaeological sites were evaluated according to the ages of the different kinds of culture in the Gansu and Qinghai area by Xie [12], Lang and An [33].

\subsection{Seed and fruit remains}

We selected and identified 26353 charred seed grains belonging to 16 plant types from the 41 flotation samples taken from the seven study sites. The cultivated plant seeds include common millet (Panicum miliaceum), foxtail millet (Setaria italica), rice (Oryza), and soybean (Glycine max), while the gathering seeds and fruit pieces include wild soybean (Glycine soja), Corylus, Castanea, Leguminosae, Cannabis, Nitrari and Chenopodiaceae, and the weed seeds include Galium, Hibiscus sp, Artemisia, Plantago, and Gramineae (Figures 2 and 3).

Table 1 AMS data for Houguanzhai and Qiaocun

\begin{tabular}{|c|c|c|c|c|c|}
\hline Lab code & Section & Depth $(\mathrm{cm})$ & Material & Uncalibrated age (a BP) & Calibrated age $(2 \delta)(\mathrm{cal}$ a BP $)$ \\
\hline OZK431 & Houguanzhai & 55 & charcoal & $175 \pm 45$ & $-3-300$ \\
\hline OZK432 & Houguanzhai & 205 & charred seed & $1210 \pm 50$ & $1051-1271$ \\
\hline OZK433 & Houguanzhai & 285 & charcoal & $4160 \pm 60$ & $4529-4837$ \\
\hline OZK434 & Houguanzhai & 375 & charcoal & $4170 \pm 50$ & $4568-4839$ \\
\hline OZK435 & Houguanzhai & 435 & charcoal & $4230 \pm 60$ & $4569-4881$ \\
\hline OZK437 & Houguanzhai & 495 & charcoal & $4150 \pm 60$ & $4526-4837$ \\
\hline OZK591 & Qiaocun & 165 & charcoal & $3720 \pm 60$ & $3912-4184$ \\
\hline OZK592 & Qiaocun & 230 & charcoal & $3790 \pm 60$ & $4072-4301$ \\
\hline OZK593 & Qiaocun & 270 & charcoal & $3655 \pm 50$ & $3855-4094$ \\
\hline OZK594 & Qiaocun & 310 & charcoal & $3705 \pm 50$ & $3906-4156$ \\
\hline
\end{tabular}

Table 2 The location, approximate age, and sample number of the study sites

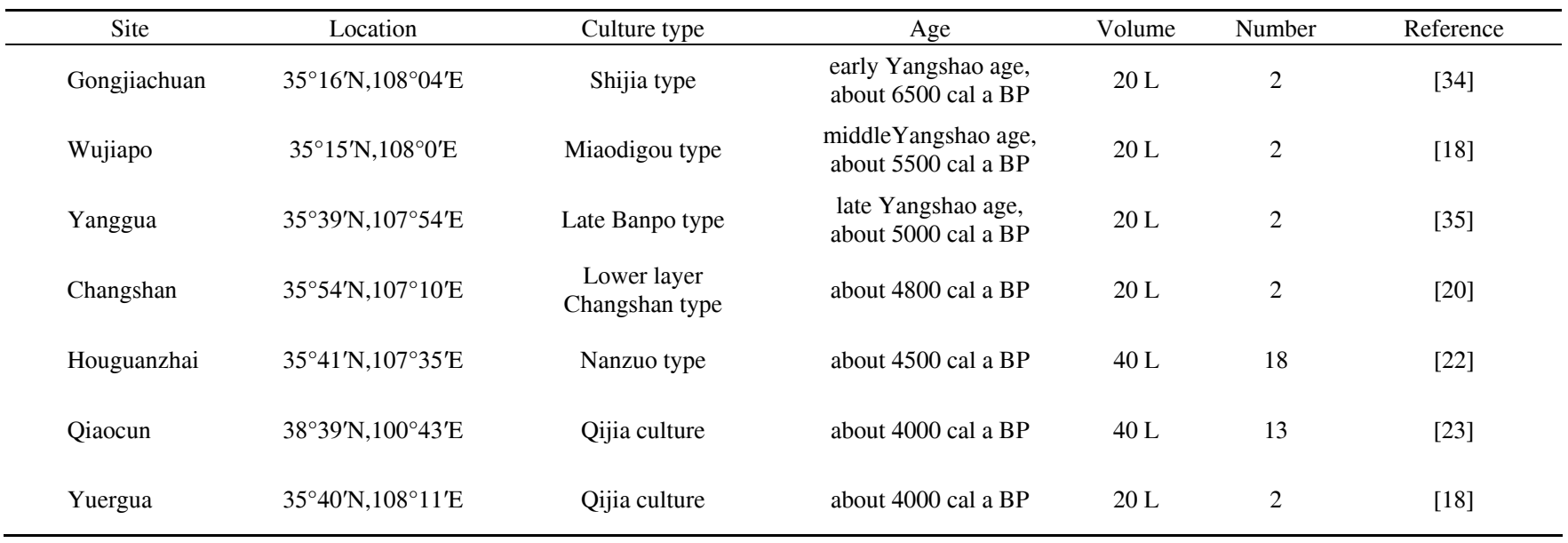




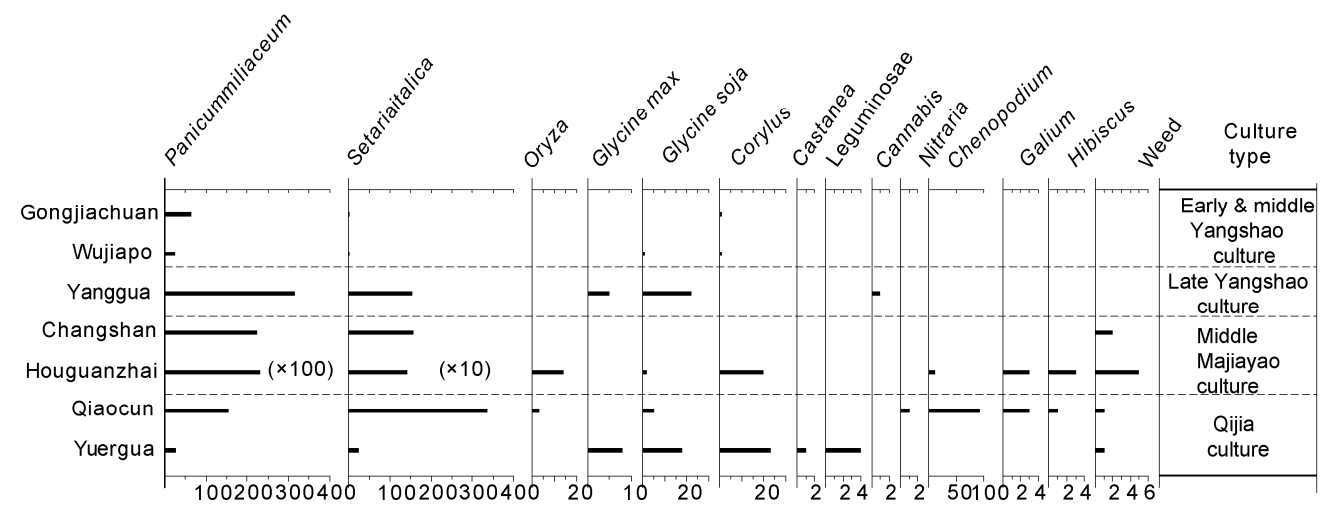

Figure 2 Species and number of seed and fruit remains in the Longdong area.

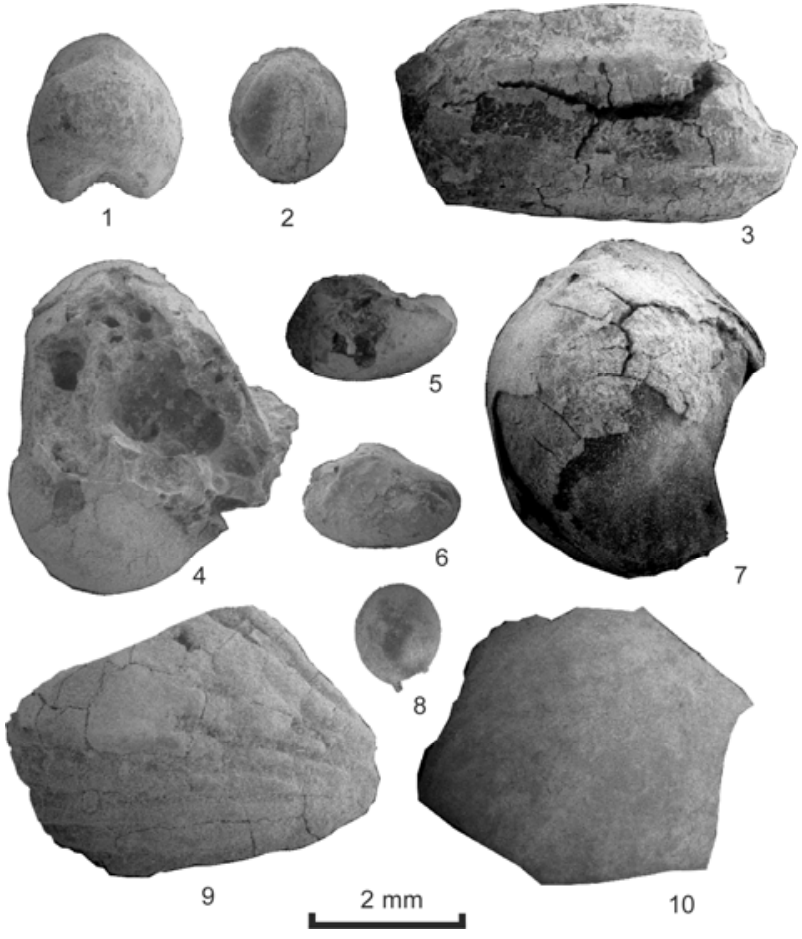

Figure 3 SEM photos of seed and fruit remains. 1, Panicum miliaceum; 2, Setaria italica; 3, Oryza sp.; 4, Glycine max; 5 and 6, Glycine soja; 7, Cannabis; 8, Chenopodiaceae; 9, Corylus (fruit shuck); 10, Castanea (fruit shuck).

Cultivated common millet seeds were the predominant seeds found, with more than $90 \%$ of the samples taken in Gongjiachuan, Wujiapo and Houguanzhai, 60\% in Yanggua and Changshan, and 25\% in Qiaocun and Yanggua. In contrast, the percentage of foxtail millet was only $3 \%$ in Gongjiachuan and Wujiapo, $31 \%$ and $41 \%$ in Yanggua and Changshan, respectively, and $56 \%$ in Qiaocun. In this last sample, foxtail millet was double the amount of common millet. Rice seeds only were present in Houguanzhai and Qiaocun, and only in very low percentages (less than 1\%). The cultivated soybean appeared in Yanggua and Yuergua, being $1 \%$ and $8 \%$ of the samples, respectively. Wild soybean, which also was found at Houguanzhai and Qiaocun, represented $4 \%$ and $17 \%$, respectively, of the total samples.
The husks of the Corylus fruit was the most common and most concentrated of all of the plant remains in this study. This plant remain was present in the samples from every site, except Yanggua. Other types of plant seeds were present mainly in the samples of Changshan, Houguanzhai, Qiaocun and Yuergua, but in very low numbers. However, Chenopodiaceous seeds appeared in a fairly large proportion, as much as $21 \%$ at Qiaocun.

\subsection{Pollen analysis}

We identified 4157 pollen grains belonging to 51 taxa in the 16 samples chosen from Houguanzhai, and 3871 pollen grains belonging to 43 taxa in the 16 samples at Qiaocun.

The pollen spectrum of the Houguanzhai section could be subdivided into three zones (Figure 4). Zone I, dated to $4800-4600 \mathrm{cal}$ a BP (the depth was $450-280 \mathrm{~cm}$ ), contained 50\% Artemisia, a high charcoal concentration, and the highest proportion of Gramineae pollen (28.8\%). In Zone II, dated to $4600-1100 \mathrm{cal}$ a BP (the depth was $280-80 \mathrm{~cm}$ ), the proportion of Gramineae pollen and charcoal concentration was less than Zone I, while the proportion of Artemisia and Chenopodiaceae was higher. Zone III contained recently cultivated soil $(80-0 \mathrm{~cm})$ where the proportion of Artemisia decreased compared to Zones I and II, and the presence of Chenopodiaceae was higher. There was approximately $2 \%$ of Ephedra pollen present in this zone.

The pollen spectrum of the Qiaocun section could be subdivided into four zones (Figure 5). Zone I was dated to earlier than $4200 \mathrm{cal}$ a BP $(380-320 \mathrm{~cm})$ and was dominated by the pollen of Artemisia and Chenopodiaceae. Also, there was a high proportion of Compositae present (approximately $11.7 \%$ on average). Arboreal pollen, including Picea, Sabina, and Quercus, and charcoal appeared only in low percentages. Zone II, dated to 4200-4000 cal a BP (320-170 cm), gradually increased in the proportion of $\mathrm{Ar}$ temisia and Chenopodiaceae, and had a high percentage of Gramineae. The amount of charcoal increased in this zone to its maximum at $1.0 \mathrm{~cm}^{2} / \mathrm{g}$ on average. Zone III was dated to after 4000 cal a BP $(170-80 \mathrm{~cm})$, and this zone had a 


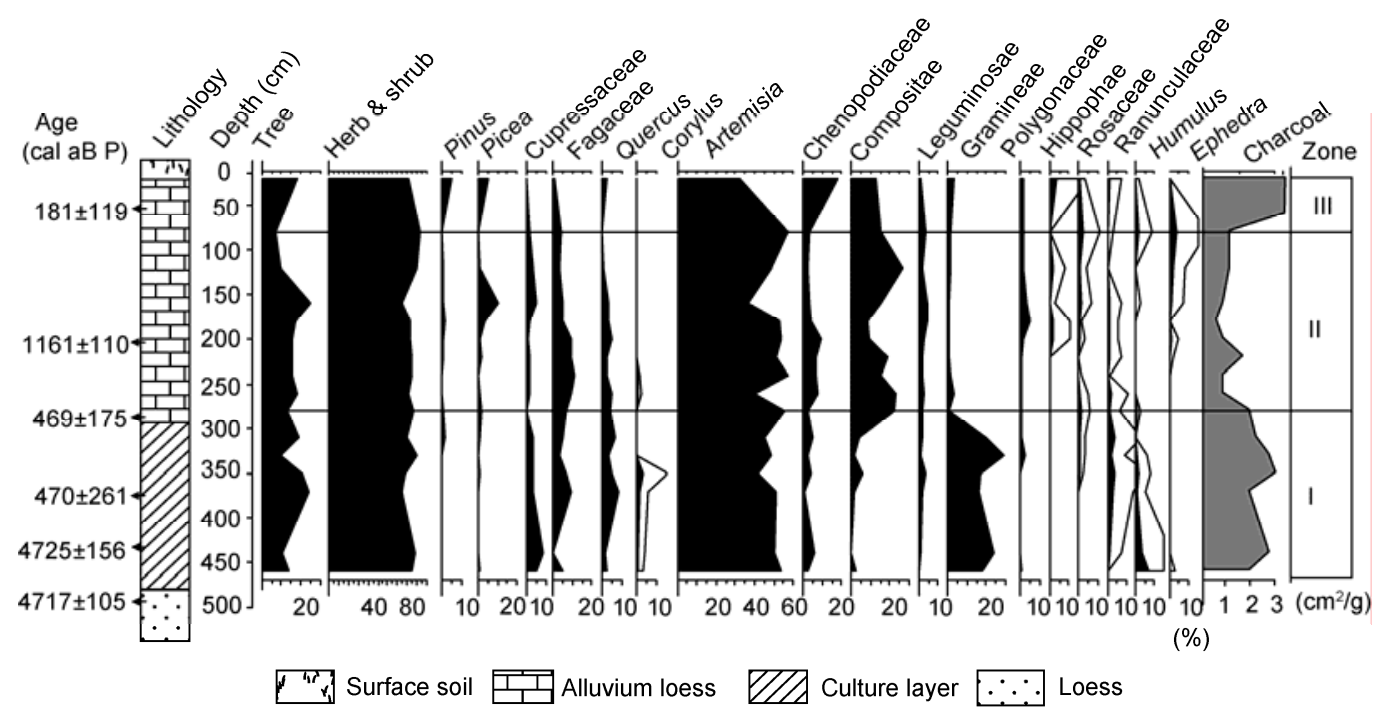

Figure 4 Pollen percentage spectrum in the Houguanzhai section.

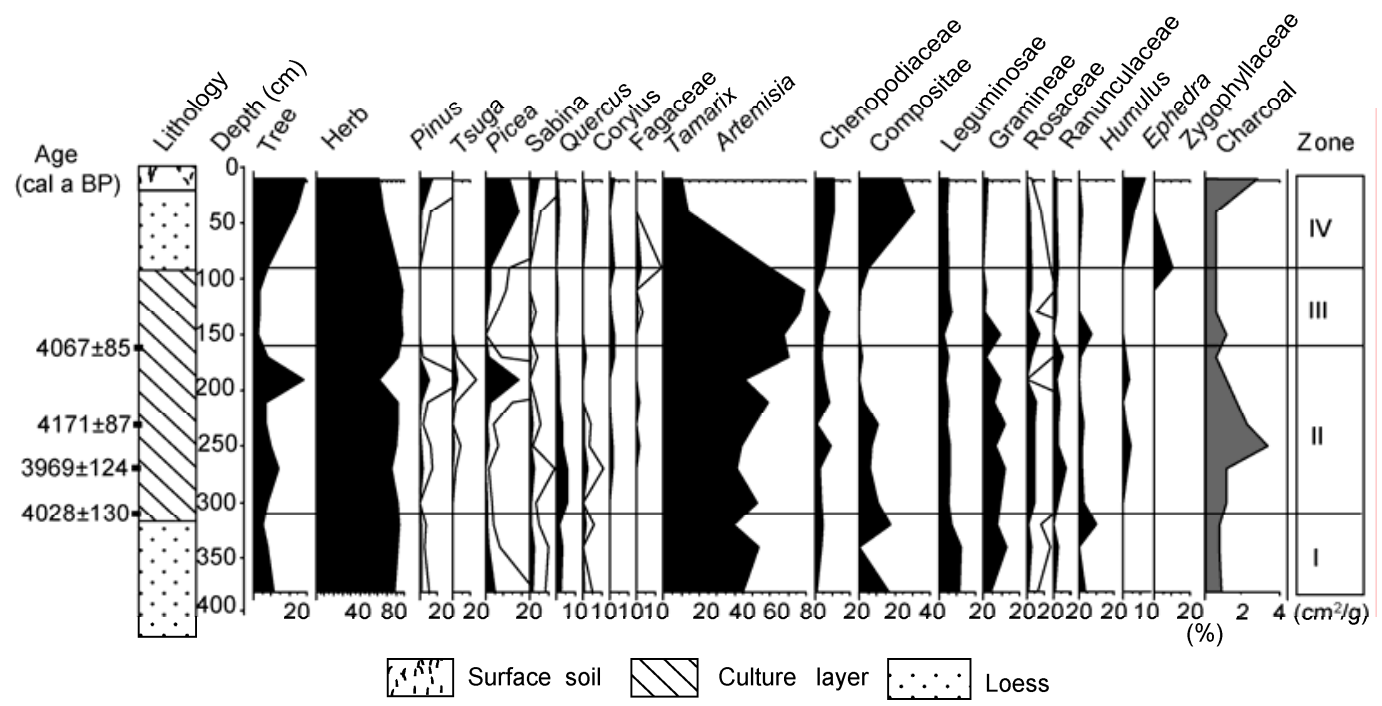

Figure 5 Pollen percentage spectrum of the Qiaocun section.

decreased proportion of arboreal pollen (down to 3\%), increased proportion of Artemisia (maximum at 74.4\%), and a significantly decreased concentration of charcoal. Zone IV contained the most recently cultivated soil $(80-0 \mathrm{~cm})$ and showed an increase in arboreal pollen, a decrease in the otherwise dominant Artemisia and Chenopodiaceae herb pollen, and the highest levels of Compositae in this area.

\section{Discussion and conclusions}

\subsection{Proportion of common millet and foxtail millet in the Neolithic Longdong area}

Common millet and foxtail millet both are important crops with a long cultivation history in dry land agricultural production of north China. They were dominant food sources for Neolithic agricultural societies in the semiarid and semi-humid area of Eastern Asia. Thus, the development of millet agriculture was significant and meaningful for the origin of Chinese civilization [6-9]. Present archaeological knowledge shows that a hunter-gatherer economy was still very important and made up a large proportion of the economic activities in early Neolithic period China. Early agriculture was normally quite simple and unvaried in the beginning of Neolithic period. Recent archaeobotanical evidence for early agriculture shows that common millet was the predominant cultivated crop for the 10000-year-old Neolithic site in Cishan, located in the middle reaches of the Yellow River [2]. Furthermore, common millet also was cultivated as the dominate crop in Xinglonggou (8000-7500 cal a BP) and Yuezhuang (7870 cal a BP) in the preYangshao Neolithic age of northern China. In addition, 
common millet was the only cultivated plant found in the layer of Dadiwan I (7800-7350 cal a BP) [6,33-35].

Similarly, although both common millet and foxtail millet were found in the flotation samples from the remains of the early and middle Yangshao periods in the Longdong basin area and their presence probability is nearly equal, this study found that common millet was dominant, whereas foxtail millet rarely appeared. These results indicate that common millet was the predominant crop of the early and middle Yangshao period and that the agricultural structure of that time was still singular. The proportion changed in the late Yangshao period as the percentage of foxtail millet exhibited an increasing trend in subsequent times. The amount of foxtail millet increased and exceeded common millet by the Qijia period (Figure 6). This phenomenon has been shown in the studies of other areas in the Yellow River valley $[6,33,36-38]$.

Although changes in the mechanism of the agricultural production of common millet and foxtail millet in Neolithic cultures still remains unclear, the difference between the characters of these two crops is undoubtedly an important factor in this process. Under normal conditions, common millet is more disease-resistant compared to foxtail millet. There are very few reports of disease and pests in common millet farmland. Conversely, foxtail millet is easily infected by diseases, such as mildew, leaf spots, and albinism $[39,40]$. After several years of continuous harvest, high density, overgrown foxtail grass (Setaria faberi) will accompany the foxtail millet growth, and the probability of infection by albinism increases 2- to 4-fold [41], and the production of foxtail millet is twice that of common millet in the morden Loess Plateau [42,43]. It is safe to say that common millet is easier to cultivate than foxtail millet because of its high competition and disease resistance, indicating that less time would be needed for the field management of common millet cultivation. Thus, it is understandable that early Neolithic farmers preferred common millet as the main species for food production in places where

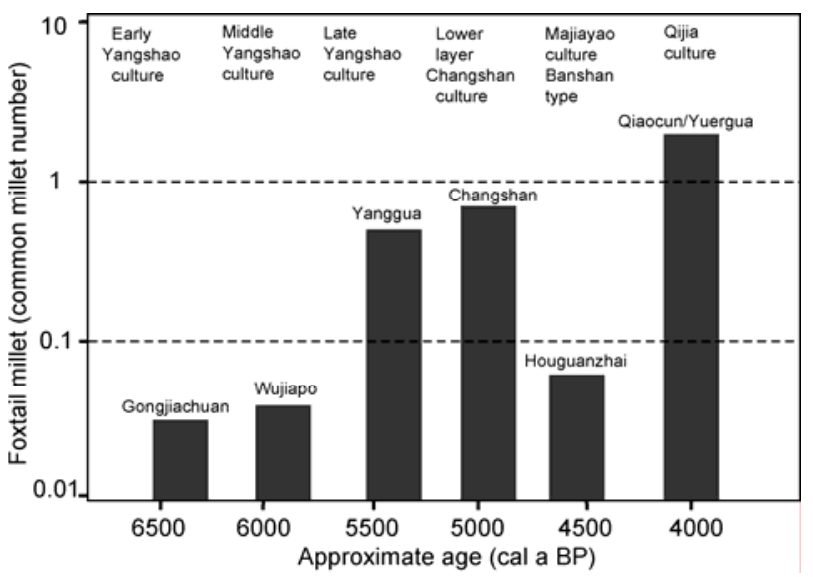

Figure 6 Proportion of common and foxtail millet through Neolithic Longdong. agricultural was not the central economic stimulus.

The greatest advantage of foxtail millet was its capacity for higher productivity compared to common millet. Recent-year average statistics show that the yield of foxtail millet is $2250-3750 \mathrm{~kg} / \mathrm{ha}$ and common millet is $750-1500$ $\mathrm{kg} / \mathrm{ha}[42,43]$. Thus, the yield of foxtail millet is double that of common millet in the loess plateau, where light and heat conditions are good. Furthermore, several recent agronomical studies have shown that the water efficiency of foxtail millet is probably higher than that of common millet, indicating that foxtail millet could utilize water more efficiently to produce seeds [44]. Thus, in semi-arid environments, foxtail millet can compensate for drought better than common millet [45].

In response to the decreasing intensity of Asian monsoons after 5000 cal a BP, the climate of northern China displayed a tendency for drought and increasing instability [46]. At the same time, the ancient societies of northern China were faced with resource shortages caused by this climate change. The amount of wild animal remains decreased in the Late Yangshao period in the west loess plateaus, indicating that the proportion of hunter-gatherers decreased in this area. At the same time, the number of agricultural implements found in excavations, such as the stone knives, stone axes, stone sickles, and both stone and bone shovels, increased greatly. This indicates a higher level of agricultural productivity and techniques, which probably related to a productive agricultural economy compared with earlier periods $[5,21]$. However, the probability that early forms of agriculture could produce adequate food for large populations, especially when only common millet was grown, is very low. In the climatological and cultural context of the Longdong basin, high yielding foxtail millet, which is more adaptable to a semi-arid climate, was chosen as the most important crop for large-scale cultivation, and exceeded common millet in proportion by the Qijia period. This kind of agricultural structure was probably widely distributed in Neolithic culture in semiarid areas of China. The noodles made from foxtail and broomcorn millet unearthed at Lajia (dating to the Qijia period) were likely derived from a similar agricultural structure [47]. Furthermore, because of its ability to produce more grain, foxtail millet was successfully domesticated on a large scale. The increased productivity of early agriculture produced a surplus of food, and allowed for the rapid development of Neolithic societies and populations. As a result, the size and number of settlements in the late Yangshao and Qijia periods were exceeded by those of early and middle Yangshao culture in the Longdong area $[48,49]$.

\subsection{Other cultivated species}

When Neolithic people faced the pressure of increasing populations and food shortages caused by climate change, it was necessary to both choose productive crop species and 
extend the spectrum of agriculture to support the population $[6,9]$. This study shows that cultivated soybeans, the seeds of which were more than twice the size of wild soybean seeds, also were cultivated as important sources of plant protein during the Neolithic period. Previous studies have shown that rice also was cultivated in Neolithic Qingyang [14]. In our study, we also found a few rice seeds in Houguanzhai and Qiaocun samples. These seeds indicate that rice was cultivated widely no later than $4800 \mathrm{cal}$ a BP in the Longdong area, although the planting proportion was probably low. Gongliu, in the Book of Songs, recorded that the ancestors of the Zhou people "harvest Chinese dates in August and rice in October", which was probably a continuation of the rice farming culture since the Neolithic age.

Chenopodiaceous and Cannabis seeds, along with Corylus and Castanea which were commonly discovered in the archaeobotanical studies of the Neolithic period, also were found as a gathering plant in the archaeological remains of sites dating to after the late Yangshao period. Chenopodium albumc and Kochiascoparia schvad, which are types of Chenopodiaceae, are the most typical gathering potherb in modern China. Chenopod seeds contained amylum, a high proportion of which is available for food. In the Qiaocun site, the high proportion of Chenopod seeds in the Qijia period layers indicates that the wild Chenopod potherb or Chenopod seed were introduced as an important food source at that time.

One Cannabis seed was found in the late Yangshao layer at Yanggua. This seed was $5.1 \mathrm{~mm}$ in length and $4.3 \mathrm{~mm}$ in width, less than half the size of modern cannabis seeds. Cannabis is widely planted in modern Gansu. Cannabis seeds have a high oil content, which can be used for food and oil, and Cannabis fiber is used for weaving. Cannabis seeds have been found previously at Linjia in the Machang period Majiayao settlements in Gansu, and Cannabis weavings also have been found in Qijia period remains [12,50]. There is still a need for further studies to determine whether the Cannabis seed found in Yanggua was cultivated or gathered.

\subsection{Environmental background and effects of early agriculture}

As mentioned above, an agricultural transition during the Neolithic period in the Longdong area developed, from producing only common millet to producing a wider range of grains, such as foxtail millet, common millet, rice, and soybeans. As the agricultural societies of the Neolithic Longdong area progressed, the size and number of settlements increased significantly, especially by the late Yangshao period. This rapid development of high-yielding agriculture also had a significant effect on the Longdong basin ecosystem.

The high proportion of herb and shrub pollen found in the Houguanzhai and Qiaocun sections indicates that the cover vegetation was dominated by grassland and shrubgrassland, while the small number of arboreal pollen, such as Picea, Tsuga, and Quercus, indicates that mixed coniferous, broad-leaf forests probably grew in these valleys. The Castanea fruit shucks found in flotation samples from Yuergua also indicate that there were Castanea-containing forests near the site. The shrub-grassland dominated tablelands, and mixed coniferous and broad-leaf forests dominated valleys, which also were identified in the pollen spectrum of Xishanping and Dadiwan. Thus, these vegetation patterns were likely to have been widely distributed in the early and late Holocene of the west Loess Plateau [51].

It is easy to develop primitive agriculture, which is based on slashing and burning, in the shrub-grass covered loess area. Because of intense agriculture activities, high proportions of crop pollen and concentrations of charcoal deposits were found in the layers or farming sediments near the settlement. Modern surface soil pollen research shows that the percentage of Gramineae in the surface soil is no more than $10 \%$, even in grass dominated land, and that the percentage of Gramineae in natural loess sediment also is normally below 10\% [52,53]. The Graminae pollen percentages of $30 \%$ in the Houguanzhai section, and $10 \%$ in the Qiaocun section, probably were the result of crop cultivation. The pattern that is observed with Gramineae pollen mimics that of charcoal concentration, which indicates the expansion and subsequent decline of "slash-and-burn" agriculture.

In addition to the generally high content of grass pollens, Artemisia pollen clearly was the most dominant in the study areas, with an average of $50 \%$ and a maximum of $80 \%$. This phenomenon probably indicates that the original shrubgrasslands were degraded by agriculture activities, and the result was a reduction of the variety of viable grasses. The decrease of Gramineae pollen and the concentration of charcoal in the upper loess layers of both study sections show that agricultural activities were either weak or terminated. At the same time, the percentages of the pollens of Ephedra, Hippophae, Chenopodiaceae, and Compositae clearly increased and were associated with a general change in the vegetation of the area. These pollen samples likely indicate that the local vegetation returned to its original, higher diversity shrub-grassland after the cessation of agricultural cultivation in these areas.

\subsection{Conclusions}

Our data demonstrate that common millet was cultivated as the predominate crop in the early and middle Yangshao culture in the Longdong area, and that high-yielding foxtail millet became widely planted in late Yangshao culture. Evidence for developing agricultural production during the late Yanshao can be seen with the cultivation of common millet, foxtail millet, soybean, and rice. The environmental effects of early agriculture on the Longdong area are seen primarily in the degradation and simplification of local 
shrub-grasslands and the expansion of cultivated Gramineae farmlands. When settlements were abandoned and systematic agriculture was terminated, the local vegetation recovered and returned to a more highly diverse landscape dominated by shrub-grasslands.

We thank Professor Liu Changjiang from the Institute of Botany of CAS for his assistance with seed identification. We also are grateful to Zhang Hongbin and Ji Ming for their assistance with our fieldwork. This work was supported by the National Basic Research Program of China (2010CB950200), the National Natural Science Foundation of China (41001062), and partly by a Special Fund of State Key Laboratory of Loess and Quaternary Geology (LQ0701).

1 Clift P D, Plumb R A. The Asian Monsoon: Causes, History and Effects. Cambridge: Cambridge University Press, 2008. 197-247

2 Lu H, Zhang J, Liu K, et al. Earliest domestication of common millet (Panicum miliaceum) in East Asia extended to 10000 years ago. Proc Natl Acad Sci USA, 2009, 106: 7367-7372

3 Kirch P V. Archaeology and global change: The Holocene record. Annu Rev Environ Resour, 2005, 30: 409-440

4 Goldberg P, Vance T H, Ferring C R. Earth Sciences and Archaeology. New York: Kluwer Academic/Plenum Publishers, 2001. 37-48

5 Yan W M. The Development of Agriculture and the Rise of Civilization Agriculture Development and the Rise of Civilization (in Chinese). Beijing: Science Press, 2000. 83-86

6 Liu C J, Jin G Y, Kong Z C. Agricultural Archaeology: Studies on Seed and Fruit (in Chinese). Beijing: Science Press, 2008. 168-170

7 Chen W H. Archaeobotany (in Chinese). Beijing: Cultural Relics Publishing House, 2002. 22-37

8 Lee G A, Crawford G W, Liu L, et al. Plants and people from the early Neolithic to Shang periods in North China. Proc Natl Acad Sci USA, 2007, 104: 1087-1092

9 Li X Q, Zhou X Y, Zhang H B, et al. The earliest archaeobiological evidence of the broadening agriculture in China recorded at Xishanping site in Gansu Province. Sci China Ser D-Earth Sci, 2007, 50: $1707-1714$

10 Zhao Z J. On the distinctive features of agricultural economy during the formation of Xia-Shang-Zhou Civilization (in Chinese). Huaxia Archaeol, 2005, 1: 75-81

11 Hu S X. Genesis and evolution of Heilu soils in the middle and east Gansu Province (in Chinese). Acta Pedol Sin, 1994, 3: 295-304

12 Xie D J. Prehistoric Archaeology in Gansu-Qinghai (in Chinese). Beijing: Cultural Relices Publishing House, 2002.111-200

13 Lang S D. The study and progress of the history of prehistoric Gansu (in Chinese). Hist Geogr NW China, 1992, 2: 1-8

14 Zhang W X, Wang H. Study of ancient domesticated rice from the Qingyang site in Gansu (in Chinese). Agric Archaeol, 2000, 3: 80-86

15 Li D L. Climate in Gansu (in Chinese). Beijing: Meteorological Publishing House. 2000. 102-110

16 Wu Z Y. Vegetation of China (in Chinese). Beijing: Science Press, 1980. 945-948

17 Li S W, Xue L G, Feng H Y et al. Types and Characteristics of Natural Grassland Vegetations in the Loess Plateau Lying in East Gansu Province (in Chinese). Acta Bot Boreal Occident Sin, 2006, 26: $805-810$

$18 \mathrm{Li} \mathrm{H} \mathrm{X.} \mathrm{A} \mathrm{brief} \mathrm{report} \mathrm{of} \mathrm{investigation} \mathrm{and} \mathrm{excavation} \mathrm{of} \mathrm{Neolithic}$ culture sites of four counties in the south Qingyang, Gansu (in Chinese). Archaeol Cult Rel,1988, 3: 6-16

19 Zhang Q L. The relationship between Majiayao culture and Yangshao culture (in Chinese). Archeology, 2002, 1: 47-61

20 Archaeological Team in the Drainage of Jinghe River and Weihe River of the institute of Archaeology Chinese Academy of Sciences. Exploring report of Changshan site in Zhenyuan Gansu (in Chinese).
Archaeology, 1981, 3: 201-211

21 Institute of Cultural Relics and Archaeology of Gansu Province. Exploring Report of Dadiwan Neolithic Site in Qin'an. Beijing: Cultural Relics Publishing House, 2006. 693-694

22 Zhao X Y. Neolithic site of Nanzuo, Xifeng (in Chinese). In: Chinese Archaeology Almanac of 1997. Beijing: Cultural Relics Publishing House, 1999. 233-234

23 Archaeological Team of Gansu Museum. A brief report of excavation in Qiaocun site, Lingtai (in Chinese). Archaeol Cult Rel, 1980, 3: 22-24

24 Sun L. Report of Excavation of Neolithic Site and Graves of Caiyuan, Ningxia (in Chinese). Beijing: Science Press, 2003

25 Schock J. Indoor water flotation - A technique for the recovery of archaeological materials. Plains Anthropol, 1971, 16: 228-231

26 Davis E M, Wesolowsky A. The Izum: A simple water separation device. J Field Archaeol, 1975, 22: 271-273

27 Zhao Z J, Fang Y M. Identification and analysis of the objects floatation selected from the soil samples collected to the Wangchenggang Site in Dengfeng (in Chinese). Huaxia Archaeol, 2007, 2: 78-89

28 Ascough P, Bird M, Francis S, et al. Alkali extraction of archaeological and geological charcoal: Evidence for diagenetic degradation and formation of humic acids. J Archaeol Sci, in press

29 Li X Q, Shang X, Zhou X Y, et al. Integrative method of sieving and heavy liquid in pollen analysis of loess (in Chinese). Arid Land Geogr, 2006, 29: 663-667

30 Clark R L. Point count estimation of charcoal in pollen preparations and thin sections of sediments. Pollen Spores, 1982, 24: 523-535

31 Li X Q, Zhou X Y, Shang X, et al. Different size method of charcoal analysis in loess and its significance in the study of fire variation (in Chinese). J Lake Sci, 2006, 18: 540-544

32 Stuiver M, Reimer P J, Bard E, et al. INTCAL 98 radiocarbon age calibration, 24000-0 cal a BP. Radiocarbon, 1998, 40: 1041-1083

33 An C B, Ji D X, Chen F H, et al. Evolution of prehistoric agriculture in central Gansu Province, China: A case study in Qin'an and Li County. Chinese Sci Bull, 2010, 55: 1925-1930

34 Qingyang Museum and Zhengning Cultural House. A Report of Investigation in Gongjiachuan Neolithic site in Zhengning, Gansu (in Chinese). Archaeol Cult Rel, 1988, 1-26

35 Qingyang Museum. A report of excavation of Yanggua site in Ningxian, Gansu (in Chinese). Archaeology, 1983, 10: 869-877

36 Zhao Z J. Discussion of the origin of dry land agriculture in northern China based on the result of flotation in Xinglongwa site. In: Department of Relics and Museology of Nanjing Normal University, eds. Antiquity of East Asia (in Chinese). Beijing: Culture and Relics Press, 2004. 188-199

37 Crawford W G, Chen X X, Wang J H, et al. Houli culture rice from the Yuezhuang Site, Jinan. East Asia Archaeol, 2006, 3: 247-252

38 Zhang J P, Lu H Y, Wu N Q, et al. Phytolith evidence of millet agriculture during about 6000-2100 a BP in the Guanzhong Basin, China (in Chinese). Quat Sci, 2010, 30: 287-297

39 Sutic D D, Ford R E, Tosic M T. Handbook of Plant Virus Diseases. London, New York, Washington: CRC Press, 1999

40 Baltensperger D D. Foxtail and proso millet. In: Janick J, ed. Progress in New Crops. Alexandria: ASHS Press, 1996. 182-190

41 Lin R F, Chai Y, Liao Q. Minor Grain Crops in China (in Chinese). Beijing: Agricultural Science \& Technology Publishing House of China, 2002

42 Chai Y, Feng B L. Present situation and developing strategies of minor grain crops in China (in Chinese). Agric Res Arid Areas, 2003, 21: $145-151$

43 Yang W Z. The productivity and increase production system of the main crops in the Loess Plateau. In: Yang W Z, Yu Z Y, eds. Regional Management and Evaluation in the Loess Plateau. Beijing: Science Press, 1992. 73-124

44 Seghatoleslami M, Kafi M, Majidi I, et al. Effect of drought stress at different growth stages on yield and water use efficiency of five proso millet (Panicum miliaceum) genotypes. Pakistan J Bot, 2008, 40: $1-4$

45 Guo X S. The compensation effect after the drought (in Chinese). Chin J Appl Ecol. 1999, 10: 563-566 
46 Wang Y J, Cheng H, Edwards R, et al. The Holocene Asian monsoon: Links to solar changes and North Atlantic climate. Science, 2005, 308: 854-856

47 Lu H Y, Yang X Y, Ye M, et al. Culinary archaeology: Millet noodles in late Neolithic China. Nature, 2005, 437: 967-968

48 An C B, Tang L Y, Barton L, et al. Climate change and cultural response around $4000 \mathrm{cal}$ a BP in the western part of Chinese Loess Plateau. Quat Res, 2005, 63: 347-352

49 Li X Q, Dodson J, Zhou J, et al. Increases of population and expansion of rice agriculture in Asia, and anthropogenic methane emissions since 5000 BP. Quat Int, 2009, 202: 41-50

50 Institute of Botany Northwest Normal University and Gansu Museum.
Millet and Cannabis excavated in site of Majiayao culture remains in the Dongxiang Linjia, Gansu (in Chinese). Archaeology, 1984, 654-655

51 Feng Z D, Tang L Y, Wang H, et al. Holocene vegetation variations and the associated environmental changes in the western part of the Chinese Loess Plateau. Palaeogeogr Palaeoclimatol Palaeoecol, 2006, 241: 440-456

52 Xu Q H, Li Y C, Yang X L, et al. Study on surface pollen of major steppe communities in northern China (in Chinese). Geogr Res, 2005, 24: $394-402$

53 Xu Q H, Li Y C, Zhao C H, et al. Surface pollen assemblages from typical shrub communities in North China (in Chinese). J Palaeogeogr, 2006, 8: 157-164

Open Access This article is distributed under the terms of the Creative Commons Attribution License which permits any use, distribution, and reproduction in any medium, provided the original author(s) and source are credited. 